\title{
Interhemispheric mediation of the following response in ducklings
}

\author{
JACK DEMAREST, NICHOLAS BRECHA, and RICHARD BRONSTEIN \\ State University of New York, Stony Brook, New York 11790
}

\begin{abstract}
The evidence for interhemispheric transfer of learned discriminations in young birds is inconsistent. In the imprinting situation, there is evidence suggesting that the discrepancy lies in the nature of the test stimuli employed. We found that interhemispheric transfer of a visual preference in monocularly imprinted Peking ducklings was not readily apparent in a simultaneous discrimination test when there was an unlearned preference for the nonimprinted object by control birds. Additional studies demonstrated that interhemispheric transfer can occur if the imprinting and novel stimulus objects are equated for their initial attractiveness. The lack of consistent transfer results in previous imprinting studies could be due to the failure to take these perceptual preferences into account.
\end{abstract}

The optic nerves in the avian visual system are completely crossed at the optic chiasma and they terminate in the contralateral mesencephalon and diencephalon (Cowen, Adamson, \& Powell, 1961; Karten \& Nauta, 1968; Karten \& Revzin, 1966). This anatomical arrangement provides an opportunity to study the bilateral organization of the central nervous system without requiring surgical intervention between the hemispheres. Interhemispheric information exchange can be investigated by training intact birds on a visual task with only one eye exposed and testing with the "untrained" eye. There are good grounds for supposing that when the visual input is restricted to one hemisphere in the young intact bird both sides of the brain retain the learned information (Cherkin, 1970; Horn, Rose, \& Bateson, 1973; Moltz \& Stettner, 1962). Recently, however, evidence unfavorable to this interpretation has been reported for visual cliff performance (Zeier, 1970) and for imprinting (Klopfer, 1973).

In an imprinting situation, a newly hatched precocial bird will rapidly learn the characteristics of the first moving object it is exposed to and may subsequently approach and follow it in preference to a novel object. A study by Moltz and Stettner (1962) reported interhemispheric transfer of an imprinting preference, but Klopfer (1973), working with the same species, failed to demonstrate transfer. We feel that significant differences in the procedures of these two studies warrant a reexamination of the transfer phenomenon with respect to imprinting. Specifically, Klopfer used as the imprinting stimulus a cardboard

This research was supported by NSF Grant 31-8301A and a Faculty Grant-in-Aid from Monmouth College. A preliminary draft of this paper profited from the criticisms and suggestions of Xenia Coulter. Dorothy Wright and Gary Wood provided assistance in testing the animals. Reprints may be obtained from Jack Demarest, Department of Psychology, Monmouth College, West Long Branch, New Jersey 07764. pyramid, and as the novel stimulus a duck decoy. Moltz and Stettner used the duck decoy as the imprinting stimulus and a cardboard cube as the novel object. The results of both experiments include a confound in that the duck decoy incorporates visual elements that apparently elicit innate (i.e., untrained) preferences in young ducklings (Hess \& Hess, 1969; Klopfer, 1967). After imprinting to a duck decoy, apparent transfer could be little more than an expression of a species-specific preference. Or, in contrast, after imprinting to a neutral stimulus, a failure to transfer could reflect a conflict between the learned response to the previously neutral stimulus and an unlearned preference for a novel duck decoy. It follows that an adequate test of transfer should involve two originally neutral stimuli. In our first study, we replicated the portion of Klopfer's (1973) experiment relevant to interhemispheric transfer. The second and third studies incorporated the same procedure but different test stimuli to determine if transfer could be demonstrated with originally neutral stimuli.

\section{EXPERIMENT 1}

\footnotetext{
Method

Subjects. Twenty-three Peking ducklings, Anas platyrhynchos, hatched in a laboratory incubator, were used. The animals were reared from eggs supplied by C \& R Duck Farms, Westhampton, New York. After hatching, the birds were isolated in individual metal cages in a dark, temperature-controlled brooder room. Food and water were available at all times.

Apparatus. Exposure to the imprinting stimulus was carried out in a circular runway apparatus, $5 \mathrm{~m}$ in circumference and $30 \mathrm{~cm}$ wide. The imprinting stimulus was suspended from an armature which revolved around the circular runway at a speed controlled by the experimenter. The armature was powered by a reversible, variable-speed motor located in the center of the runway. Burlap curtains screened the experimenter from the bird's view. A green cardboard pyramid, $30 \mathrm{~cm}$ high and $15 \mathrm{~cm}$ wide at the base, served as the imprinting model.

Testing was done with two stimuli suspended $180^{\circ}$ apart in
} 


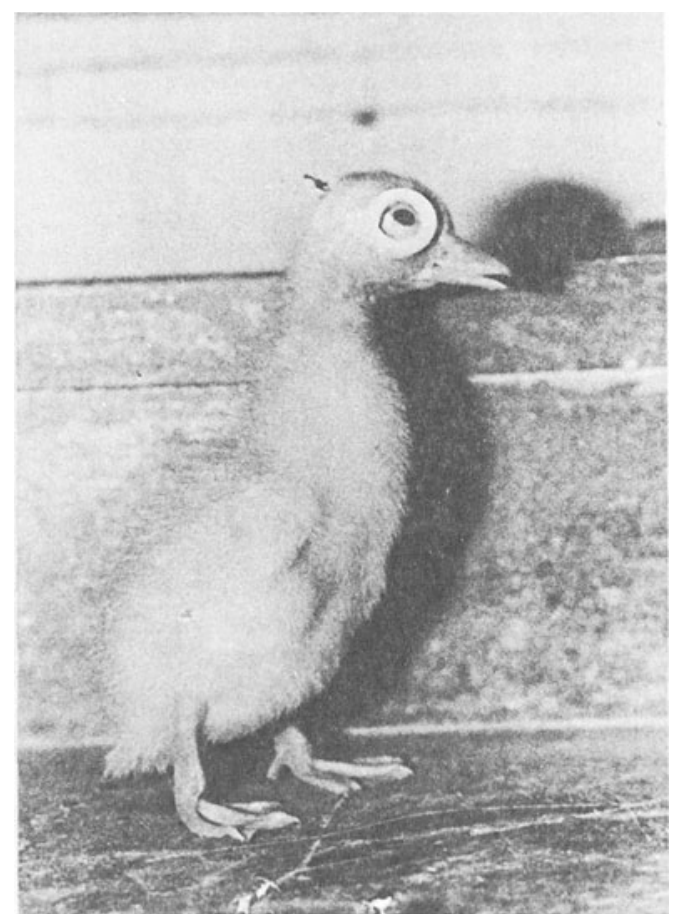

Figure 1. Photograph of a 5-day-old duckling wearing an eyepatch. The outer cover has been removed to reveal the viewing aperture.

the circular runway. One stimulus was the imprinting model and the other was an adult-size duck decoy, similar to that used by Klopfer (1973), painted white and cross-hatched at 2-cm intervals with alternate red, blue, yellow, and green colored strips of plastic adhesive. Both the imprinting stimulus and the novel stimulus were suspended approximately $1-2 \mathrm{~cm}$ above the runway floor.

The foundation for the eyepatch used to occlude the duckling's vision was made of a soft foam rubber (Scholl's corn pads) with a center aperture approximately $8 \mathrm{~mm}$ wide through which the animal could see (see Figure 1 ). The pad was securely attached around the eye with the aid of an eyelash adhesive. During monocular imprinting, the aperture was covered with a piece of black plastic tape which completely sealed off ambient light.

Procedure. Within $1 \mathrm{~h}$ of hatching, the birds were removed from the incubator and isolated in the dark rearing cages. Exposure to the training conditions occurred initially at approximately $15 \mathrm{~h}$ after hatching (range, 13-18 h). The eight monocular animals were fitted with an eyepatch over the left eye at hatching and were trained and tested with the right eye. The seven nontrained control animals were similarly treated, except that they were exposed to an empty apparatus at the usual training age. The eight interocular animals were fitted with an eyepatch on the right eye at hatching and were monocularly trained with the left eye. At testing, the eyepatch was placed over the left eye and transfer was examined with the right eye exposed. Since hemispheric dominance was not an issue in this experiment, we did not include counterbalanced exposure eye groups. When the animals were not being trained or tested, the outer covering of each patch was removed to reveal an aperture through which the birds could see.

At the first exposure session, each bird was carried in the dark to the apparatus and placed next to the imprinting model. The apparatus lights were then turned on and the stimulus was put in motion. It was moved back and forth next to the bird for $15 \mathrm{~min}$ or until the bird began to follow. Notes were kept of the bird's reaction to the object as it approached the blind side and the viewing side of the animal. Three additional 15-min sessions were given on Days 2-4 posthatch. All birds which failed to follow within $30 \mathrm{~cm}$ of the imprinting model for at least $80 \%$ of the final training session were eliminated from the experiment. Three animals, two from the monocular group and one from the interocular group, were omitted for failing to meet this criterion. Testing was done on Day 5 posthatch. The duckling was placed equidistant from the two test stimuli in the dark. The initial position of the two stimuli on the left or right of the animal was counterbalanced within each group. When the apparatus was illuminated, the animal could view both objects and approach either one. Ten seconds later, the objects were put in motion and, for all practical purposes, the bird could only see one object at a time as it rotated past. The stimuli always rotated in a clockwise direction, and therefore the counterbalancing procedure meant that for half of the animals in each group the imprinting stimulus would approach the duckling first, while for the other half of the animals the novel stimulus would approach first. The test stimuli were rotated at a constant speed (i.e., $4 \mathrm{rpm}$ ), and the amount of time an animal followed each model in four 5-min intervals was recorded. The 5-min intervals were separated by a $30-\mathrm{sec}$ blackout. The stimuli were rotated $90^{\circ}$ clockwise during the blackout so that at the beginning of every test interval the ducklings were presented with a simultaneous discrimination problem. It should be noted that ducklings, like many diurnal birds, will remain stationary in the dark (Welty, 1975). "Following" was defined in this study and those that follow as movement by the bird in the same direction as the stimuli within $30 \mathrm{~cm}$ of the side or rear of one of them. The amount of time spent running in front of a stimulus was not recorded.

\section{Results}

The notes from the acquisition phase verified that the eyepatches were effective in blocking all vision in that eye. Every animal's head oriented and turned as the imprinting object approached and rotated past the viewing side of the bird, but no animal oriented or gave any indication of seeing the approaching object from the covered wide. If the bird ran in front of the object while it was following so that the model was on the covered side, the bird invariably stopped and began to give distress calls. This never occurred while the model was on the viewing side of the animal.

The median amount of time that the birds followed each test model during the last two 5-min intervals of training and during the four 5-min test intervals is shown in Figure 2. Mann-Whitney $U$ test on the test period results revealed that the interocular group followed the imprinting model significantly more than the nontrained control group $(\mathrm{p}<.001)$, but considerably less than the monocular control group $(\mathrm{p}<.004)$. The nontrained control animals developed following behavior over the 20-min test session, but only with respect to the painted duck decoy. The interocular animals also increasingly followed the duck decoy over the 20-min test interval, such that there was no significant difference in the amount of time they followed the imprinting model or the unfamiliar duck decoy.

\section{Discussion}

The lack of a clear preference for the original 


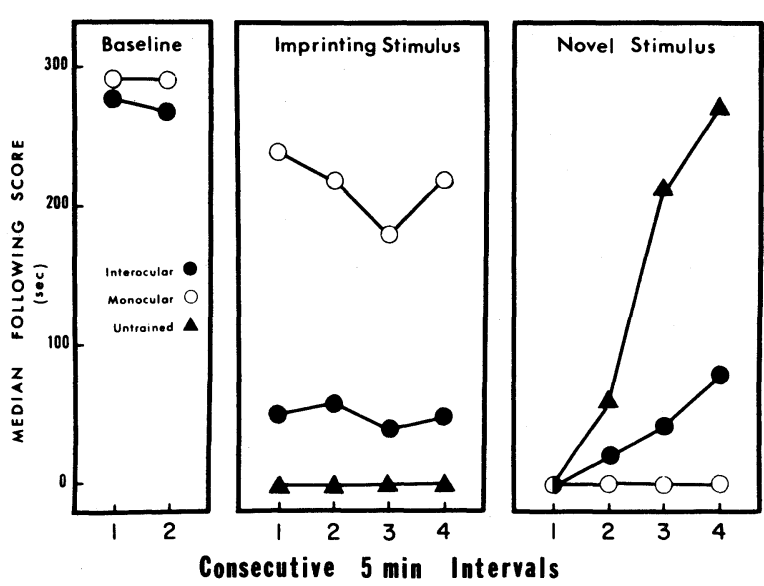

Figure 2. Median amountof time following in the final imprinting session, i.e., baseline, and during the discrimination test. (Novel stimulus $=$ duck decoy.)

training stimulus in the interocular group might suggest the conclusion that there is no interhemispheric mediation of imprinting preferences. However, development of a preference by the nontrained animals for the painted duck decoy supports the view that this decoy is a "generally prepotent" stimulus for following (Hess \& Hess, 1969; Klopfer, 1967). The apparent lack of transfer in the sense of no clear preference for the imprinted object by the interocular group could be the result of the prepotent attractiveness of the decoy. This attraction would effectively neutralize the expression of a learned preference mediated by interhemispheric transfer.

In the second and third experiments, the test setting was designed to avoid conflict between trained and untrained perceptual preferences. Experiment 2 determined that two cardboard models, a green pyramid as in the previous study and a red hexahedron, were equally attractive to ducklings. These were used as the imprinting stimulus and novel stimulus in Experiment 3.

\section{EXPERIMENT 2}

\section{Method}

Subjects and Apparatus. Twenty-four ducklings, hatched and reared the same as in the first experiment, were used in this study. Twelve of the birds were fitted with eye pads attached around both eyes within $6 \mathrm{~h}$ of hatching. The patch covering the aperture in the center of the pad was removed until training. The other 12 birds were trained without eye patches. The imprinting stimulus for half of each of these groups was the green cardboard pyramid used previously, and the imprinting stimulus for the remaining birds was a red cardboard hexahedron, $3 \mathrm{~cm}$ high and $15 \mathrm{~cm}$ wide at the base.

Procedure. The procedure was similar to the first study. The animals were individually exposed to the imprinting stimulus approximately $15 \mathrm{~h}$ after hatching for a period of $15 \mathrm{~min}$. Three additional sessions were given on Days 2-4 posthatch. All the monocularly trained birds viewed the stimulus with the right eye, the remaining birds were trained binocularly. On the 5th day after hatching, the animals were exposed to the two test stimuli for $20 \mathrm{~min}$ and the amount of time following each stimulus over each successive 5-min test interval was recorded.

\section{Results}

The median amount of time that the birds followed each test stimulus during each 5-min test interval is shown in Table 1. Mann-Whitney $U$ tests on the test period results failed to reveal any statistically significant differences in following behavior attributable to the two imprinting stimuli. Both the monocularly trained birds and the binocularly trained birds preferred the imprinting stimulus significantly more than the novel stimulus $(p<.001)$, but the performances of the birds imprinted on the red hexahedron were not different from the performances of the birds imprinted on the green pyramid.

\section{Discussion}

These results indicate that the green pyramid and the red hexahedron do not elicit differential stimulus preferences, preferences which may have been a factor in the results of the first experiment. This suggests that these two stimuli are equally attractive to the ducklings. In the third experiment, the green pyramid was used as the imprinting stimulus and the red hexahedron was used as the novel stimulus, thus ensuring that the interhemispheric transfer problem would not be confounded by differences in the initial attractiveness of the stimulus choices.

\section{EXPERIMENT 3}

\section{Method}

Subjects and Apparatus. Forty-three ducklings, hatched and

Table 1 Median Amount of Time Following the Imprinting and Novel Object During the Discrimination Test

\begin{tabular}{|c|c|c|c|c|c|c|c|c|}
\hline \multirow{3}{*}{$\begin{array}{l}\text { Imprinting } \\
\text { Stimulus }\end{array}$} & \multicolumn{8}{|c|}{ Test Stimulus } \\
\hline & \multicolumn{4}{|c|}{ Imprinting Object } & \multicolumn{4}{|c|}{ Novel Object } \\
\hline & $1^{*}$ & 2 & 3 & 4 & 1 & 2 & 3 & 4 \\
\hline & & & & onoc & & & & \\
\hline \multirow[t]{2}{*}{$\begin{array}{l}\text { Green Pyramid } \\
\text { Red Hexahedron }\end{array}$} & $\begin{array}{l}226 \\
224\end{array}$ & $\begin{array}{l}236 \\
231\end{array}$ & $\begin{array}{l}206 \\
228\end{array}$ & $\begin{array}{l}203 \\
210\end{array}$ & $\begin{array}{l}48 \\
24\end{array}$ & $\begin{array}{l}23 \\
32\end{array}$ & $\begin{array}{l}37 \\
11\end{array}$ & $\begin{array}{l}54 \\
53\end{array}$ \\
\hline & \multicolumn{8}{|c|}{ Binocular Birds } \\
\hline $\begin{array}{l}\text { Green Pyramid } \\
\text { Red Hexahedron }\end{array}$ & $\begin{array}{l}140 \\
162\end{array}$ & $\begin{array}{l}209 \\
202\end{array}$ & $\begin{array}{l}249 \\
235\end{array}$ & $\begin{array}{l}292 \\
280\end{array}$ & $\begin{array}{l}76 \\
54\end{array}$ & $\begin{array}{l}71 \\
43\end{array}$ & $\begin{array}{l}49 \\
33\end{array}$ & $\begin{array}{l}0 \\
0\end{array}$ \\
\hline
\end{tabular}


reared the same as in the first study, were used in this experiment. The eyepatches were placed over both eyes within $6 \mathrm{~h}$ of hatching, and vision was occluded during training and testing by covering the aperture of the patch with plastic adhesive tape.

Procedure. The procedure was similar to that of the first study, except that the animals were given a $1 / 2-h$ training session at 15-30 $\mathrm{h}$ after hatching and were returned to the training situation $24 \mathrm{~h}$ later for a second session, $1 \mathrm{~h}$ in length. This procedural change from the first study was required because of scheduling constraints placed on the use of the apparatus. We believe that the results of Experiments 1 and 3 are comparable, however, since the baseline performance of the monocular and interocular groups were not statistically different from one study to the other, and the monocular test performances in the two studies were the same. Birds that failed to follow on the first training session were omitted from the experiment. Eleven out of 36 monocularly trained birds failed to meet this criterion. Three more birds were eliminated because they pulled off the plastic cover on the eyepatch. Of the remaining animals, 11 were assigned to the monocular group and 11 to the interocular group. Nine birds were included in the nontrained control group. A fourth group of 12 animals was added simply to determine a reference level for normally treated birds. These ducklings were trained and tested binocularly. Transfer tests were given on Day 3 posthatch, requiring the ducklings to choose between the green imprinting stimulus and the novel red hexahedron. As in the previous study, all of the evidence showed that the eyepatches were effective in blocking vision in that eye.

\section{Results}

The median following scores for each group during the last $10 \mathrm{~min}$ of training and during the $20 \mathrm{~min}$ of testing are shown in Figure 3. It is again clear that the preference for the imprinted object by the interocular group was intermediate and significantly different from that of the monocular group $(p<.001)$ and the nontrained control group $(\mathrm{p}<.001$, MannWhitney U tests). A Kruskal-Wallis one-way analysis of variance revealed significant training group effects for the amount of time that the birds followed the imprinting stimulus $[\mathrm{H}(3)=107, \mathrm{p}<.001]$ but not for the amount of time that they followed the novel stimulus. In fact, none of the four groups showed any tendency to follow the novel stimulus. A comparison of following scores for the interocular group with the imprinting model and with the novel model was highly significant $(p<.001$, Mann-Whitney $U$ test $)$, indicating that the perceptual preference learned during imprinting does transfer from one hemisphere to the other when the test stimuli have been equated for attractiveness beforehand. Furthermore, a comparison of the performance of the nontrained control animals with the duck decoy stimulus in Experiment 1 and the red hexahedron in Experiment 2 showed that the duck decoy produced far more following behavior $[\mathrm{H}(1)=16.81, \mathrm{p}<.001]$.

\section{GENERAL DISCUSSION}

These experiments, taken together, indicate that there is interhemispheric mediation of the cues responsible for the elicitation of the following response in young ducklings. This mediation in an imprinting

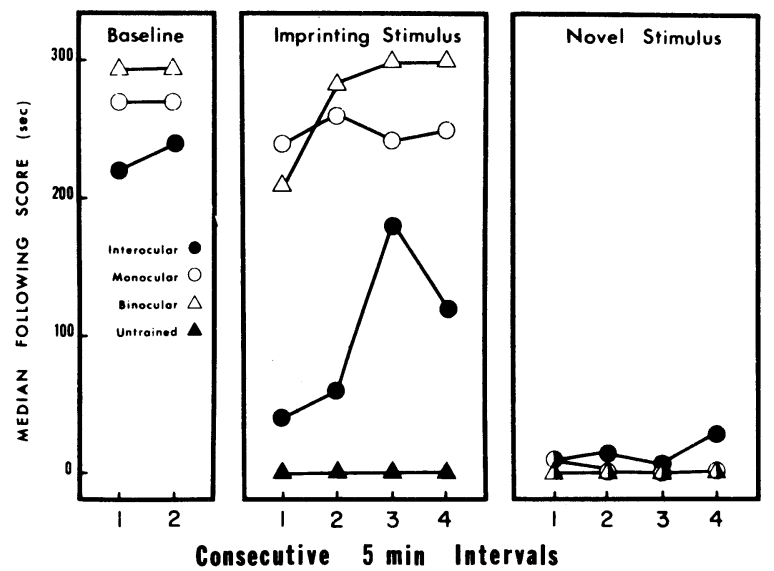

Figure 3. Median amount of time following in the final imprinting session, i.e., baseline, and during the discrimination test. (Novel stimulus $=$ red hexahedron.)

situation is consistent with previous reports of transfer using young intact birds (Cherkin, 1970; Horn et al., 1973; Moltz \& Stettner, 1962). In addition, these data extend the hypothesis proposed by Zeier (1970) that "tasks involving responses for which there is a strong inherent disposition are more easily transferred from eye to eye than are reactions that run counter to an innate response tendency" (p. 708). To these unlearned response tendencies, we should also add unlearned perceptual preferences. When there is conflict between the learned preference for the imprinting stimulus and an unlearned perceptual preference for the novel object, discrimination tests may not reveal authentic interhemispheric transfer.

It should be emphasized that unlearned perceptual preferences, as we have called them in this paper, need not necessarily suggest a species-specific releasing schema of the sort proposed by ethologists (e.g., Graves, 1973; Hess \& Hess, 1969; Lorenz, 1935; Shapiro, 1977; Shapiro \& Agnew, 1975). We do not claim to have demonstrated the sort of perceptual mechanism for supraindividual identification of the species that Gottlieb (1965) reported for the auditory mode in ducklings. In fact, any significant difference in the initial conspicuousness of the trained and untrained stimuli may produce differences in attractiveness (cf. Hailman, 1959; Klopfer, 1967) and result in the same sort of conflict in interhemispheric transfer.

However, even when transfer can be clearly demonstrated, the degree of transfer appears to be less than perfect. Only 5 of the 18 birds in the interocular groups of these two experiments showed as strong a preference with the transfer eye as with the original exposure eye. This same effect has also been reported with adult birds and with fish in visual discrimination tasks (cf. Ingle, 1968; Stettner, 1974). Why better performance is exhibited using the "trained" eye 
instead of the "untrained" eye is not, as yet, clearly understood.

\section{REFERENCES}

Cherkin, A. Eye to eye transfer of an early response moditication chicks. Nature, 1970, 227, 1153.

Cowan, W. M.. Adamson, L.. \& Powell, T. P. S. An experimental study of the avian visual system. Journal of Anatomy, 1961, 95, 545-563.

Gotтlieb, G. Imprinting in relation to parental and species identification in avian neonates. Journal of Comparative and Physiological Psychology, 1965, 59, 345-356.

Graves, H. B. Early social responses in Gallus: A functional analysis. Science, 1973, 182, 937-939.

Hailman, J. P. Why is the wood duck strikingly colorful? American Naturalist, 1959, 93, 383-384.

Hess, E. H., \& Hess, D. B. Innate factors in imprinting. Psychonomic Science, 1969, 14, 129-130.

Horn, G., Rose, S. P. R., \& Bateson, P. P. G. Experience and plasticity in the central nervous system. Science, 1973, 121, 506-514.

INGLE, D. J. Interocular integration of visual learning in goldfish. Brain, Behavior and Evolution, 1968, 1, 58-85.

KARTEN, H. J., \& Revzin, A. M. The afferent connections of the nucleus rotundus in the pigeon. Brain Research, 1966, 2, 368-377.
KARTEN, H. J., \& NaUta, W. J. H. Organization of the retinothalamic projections in the pigeon and owl. Anatomical Record, 1968, 160, 373. (Abstract)

KLOPfer. P. H. Stimulus preferences and imprinting. Science, 19h7. 156, 1394-1396.

KLOPFER, P. H. Imprinting: Monocular and binocular cues in object discrimination. Journal of Comparative and Physiological Psychology, 1973, 84, 482-487.

Lorenz, K. Der Kumpan in der Umwelt des Vogels. Journal of Ornithology, 1935, 83, 137-213, 289-413.

Moltz, H., \& STetTner, L. J. Interocular mediation of the following response after patterned-light deprivation. Journal of Comparative and Physiological Psychology, 1962, 55, 626-632.

SHAPIRO, L. J. Developing preferences for live female models of the same or other species in white Peking ducklings. Animal Behaviour, 1977, in press.

Shapiro, L. J., \& Agnew, R. L. The development of preferences for live models in white peking ducklings. Bulletin of the Psychonomic Society, 1975, 5, 140-142.

STETTNER, L. J. The neural basis of avian discrimination and reversal learning. In I. J. Goodman \& M. W. Schein (Eds.), Birds: Brain and behavior. Academic Press: New York, 1974. Pp. 165-201.

Welty, J. C. The life of birds. Philadelphia: Saunders, 1975.

ZEIER, H. Lack of eye to eye transfer of an early response modification in birds. Nature, 1970, 225, 708-709.

(Received for publication February 17, 1977; revision accepted July $21,1977$. 